\title{
Functional Circuitry of the Retinal Ganglion Cell's Nonlinear Receptive Field
}

\author{
Jonathan B. Demb, Loren Haarsma, Michael A. Freed, and Peter Sterling \\ Department of Neuroscience, University of Pennsylvania School of Medicine, Philadelphia, Pennsylvania 19104-6058
}

A retinal ganglion cell commonly expresses two spatially overlapping receptive field mechanisms. One is the familiar "center/ surround," which sums excitation and inhibition across a region somewhat broader than the ganglion cell's dendritic field. This mechanism responds to a drifting grating by modulating firing at the drift frequency (linear response). Less familiar is the "nonlinear" mechanism, which sums the rectified output of many small subunits that extend for millimeters beyond the dendritic field. This mechanism responds to a contrastreversing grating by modulating firing at twice the reversal frequency (nonlinear response). We investigated this nonlinear mechanism by presenting visual stimuli to the intact guinea pig retina in vitro while recording intracellularly from large brisk and sluggish ganglion cells. A contrast-reversing grating modulated the membrane potential (in addition to the firing rate) at twice the reversal frequency. This response was initially hyperpolarizing for some cells (either ON or OFF center) and initially depolarizing for others. Experiments in which responses to bars were summed in-phase or out-of-phase suggested that the single class of bipolar cells (either ON or OFF) that drives the center/surround response also drives the nonlinear response. Consistent with this, nonlinear responses persisted in OFF ganglion cells when $\mathrm{ON}$ bipolar cell responses were blocked by L-AP-4. Nonlinear responses evoked from millimeters beyond the ganglion cell were eliminated by tetrodotoxin. Thus, to relay the response from distant regions of the receptive field requires a spiking interneuron. Nonlinear responses from different regions of the receptive field added linearly.

Key words: in vitro retina; guinea pig; nonlinear subunit; shift effect; spiking amacrine cell; bipolar cell; tetrodotoxin; L-AP-4
A retinal ganglion cell encodes information from at least two computational mechanisms. One is familiar, the "linear" receptive field, which computes local temporal contrast by combining excitatory and inhibitory signals over both a narrow region (the "center") and a wider region (the antagonistic "surround") (Barlow, 1953; Kuffler, 1953; Rodieck, 1965; Enroth-Cugell and Pinto, 1970). The other mechanism is less familiar, the "nonlinear" receptive field, which computes global changes in contrast magnitude by summing signals from independent regions ("subunits") (Enroth-Cugell and Robson, 1966; Hochstein and Shapley, 1976; Victor and Shapley, 1979a; Cox and Rowe, 1996). The subunit, described in detail for the cat's Y $(\alpha)$ cell, is considered nonlinear because it increases activity to a contrast increment more than it decreases activity to a contrast decrement (or vice versa); in other words, the subunit rectifies its input signal (Hochstein and Shapley, 1976; Victor, 1988). The subunit covers a region narrower than the ganglion cell's dendritic field, but the mosaic of subunits is much broader, extending for millimeters beyond the dendritic field. When the visual scene contains mostly high spatial frequencies, the nonlinear receptive field can dominate the ganglion cell's output to the brain (Enroth-Cugell and Robson, 1966; Hochstein

\footnotetext{
Received June 14, 1999; revised Aug. 18, 1999; accepted Sept. 7, 1999.

This work was supported by National Institutes of Health, National Eye Institute Grants F32-EY06850 (J.B.D.), T32-EY07131 (L.H.), EY11138 (M.A.F.), and EY00828 (P.S.).

We thank Robert Smith and Yen-Hong Kao for technical advice, Madeleine Johnson for technical assistance, and Sharron Fina for help in preparing this manuscript.

Drs. Demb and Haarsma contributed equally to this work.

Correspondence should be addressed to Dr. Jonathan B. Demb, Department of Neuroscience, University of Pennsylvania School of Medicine, 123 Anatomy/Chemistry Building, Philadelphia, PA 19104-6058. E-mail: demb@retina.anatomy. upenn.edu.

Copyright (C) 1999 Society for Neuroscience $\quad 0270-6474 / 99 / 199756-12 \$ 05.00 / 0$
}

and Shapley, 1976; Derrington et al., 1979; Victor and Shapley, 1979a).

Although the circuit for the center/surround receptive field is fairly well understood, the circuit for the nonlinear receptive field remains to be elucidated (Wässle and Boycott, 1991; Sterling, 1998). One would like to know: how does the subunit rectify; how does its signal travel millimeters across the retina; and how do signals from multiple subunits combine at the ganglion cell? To answer these questions, we recorded intracellularly from ganglion cells in the intact guinea pig retina in vitro. There, we could apply antagonists to transmitter receptors and ion channels to manipulate specific aspects of the circuit.

\section{MATERIALS AND METHODS}

In vitro retina. Our experiments employed a superfused, flattened preparation of the intact mammalian retina (Jensen, 1991; Dacey and Lee, 1994). A guinea pig (350-700 gm) was anesthetized with ketaminexylazine and overdosed with pentobarbital. Both eyes were enucleated in room light and placed in oxygenated (95\%-5\% carboxy mixture) Ames medium (Sigma, St. Louis, MO) with sodium bicarbonate $(1.9 \mathrm{gm} / \mathrm{l})$ and glucose $(0.8 \mathrm{gm} / \mathrm{l})$. Each eye was hemisected, and the anterior half (cornea, lens, and vitreous) was gently peeled away from the posterior eyecup. The retina, with pigment epithelium, choroid, and sclera still attached, was flattened by cutting five to six radial slits and applied scleral side down to filter paper. The retina was placed in a chamber on the stage of an upright microscope and superfused $(2-3 \mathrm{ml} / \mathrm{min})$ with oxygenated Ames medium at $34^{\circ} \mathrm{C}$. Drugs dissolved in superfusate were kept in reservoirs connected by valves to the chamber. Agents used were tetrodotoxin (TTX) (Sigma) and L-2-amino-4-phosphonobutyric acid (LAP-4) (Research Biochemicals, Natick, MA). Glass electrodes (tip resistance of $150-400 \mathrm{M}[\mathrm{SCAP}] \Omega$ ) were filled with $1 \%$ pyranine (Molecular Probes, Eugene, OR) to visualize the pipette tip and 2\% Neurobiotin (Vector Laboratories, Burlingame, CA) in $1 \mathrm{M} \mathrm{KCl}$ buffered with $0.1 \mathrm{M}$ Tris, pH 7.4. In some experiments, lidocaine $N$-ethyl bromide (QX-314) (Research Biochemicals) was added to the pipette solution.

Intracellular recording. To visualize ganglion cells, 5-10 drops of acri- 

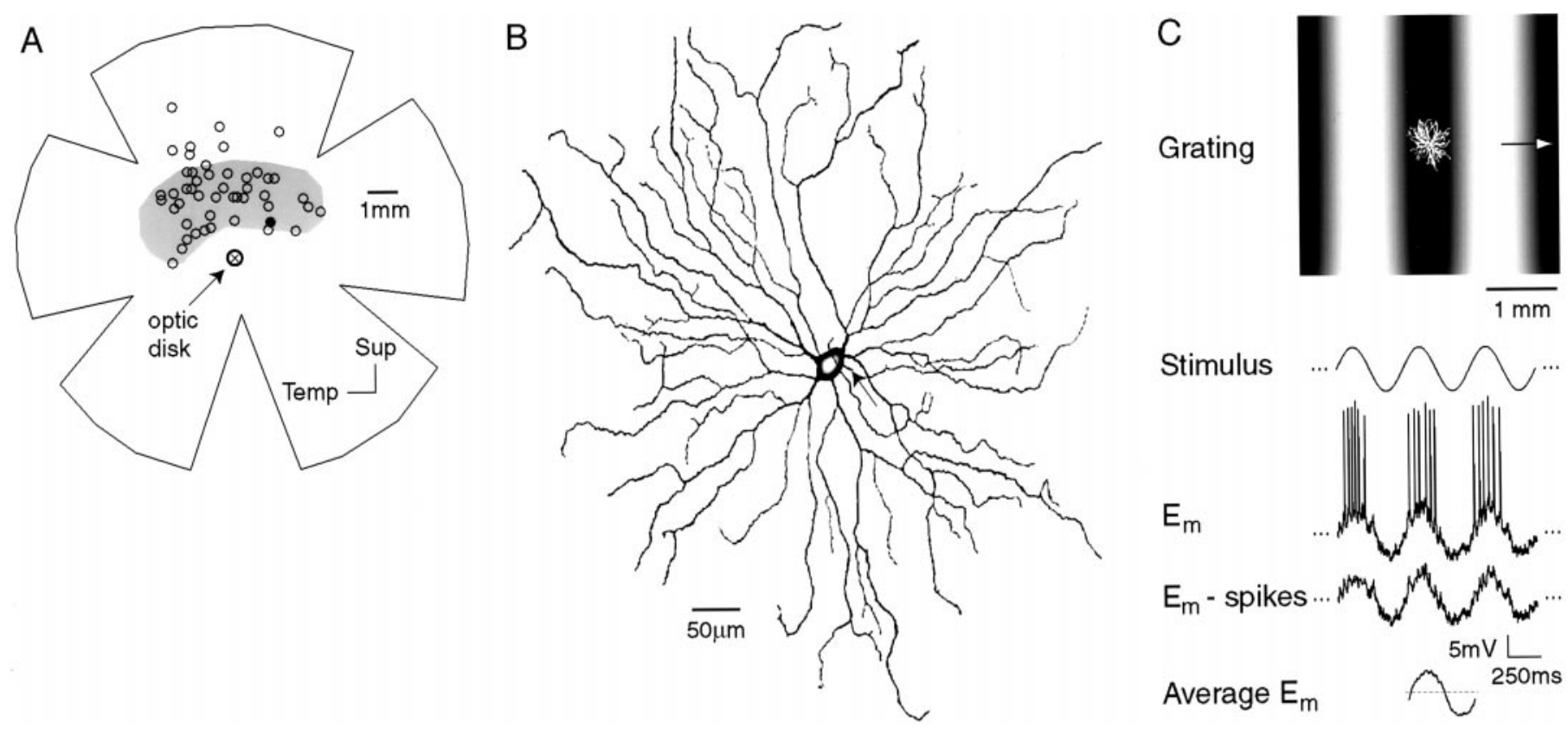

Figure 1. Ganglion cells were studied in the visual streak. A, Schematic of flattened retina showing visual streak (shaded region), location of recorded cells (open circles), and location of cell in $B$ ( filled circles). B, ON center ganglion cell (arrow marks axon). $C$, As a sine wave grating drifts over a ganglion cell, each bright phase evokes depolarization and spiking. To measure the response in the membrane potential, spikes were removed by linear interpolation (see Materials and Methods), and 20 consecutive cycles were averaged. In the following figures, unless noted otherwise, gratings are sinusoidal, $100 \%$ contrast, and presented at $2 \mathrm{~Hz}$; central gratings are $0.5 \mathrm{~mm}$ OD; peripheral gratings are $2.5 \mathrm{~mm}$ inner diameter (ID). Coarse gratings (low spatial frequency) are 1.1 cycles/mm; fine gratings (high spatial frequency) are $4.3 \mathrm{cycles} / \mathrm{mm}$. The gray dashed line indicates the average resting potential measured immediately before and $1 \mathrm{sec}$ after the stimulus was presented.

dine orange $(0.001 \%$; Molecular Probes) were added to the superfusate. Dye accumulated in ganglion cell somas and fluoresced to near-UV light (400-440 nm) from a $50 \mathrm{~W}$ mercury arc lamp transmitted through the microscope's $40 \times$ objective. Large somas $(15-25 \mu \mathrm{m}$ in diameter) in the visual streak were selected for intracellular recording. The membrane potential was amplified (NeuroData IR-283; NeuroData Instruments Corp., Delaware Water Gap, PA), continuously sampled at $2 \mathrm{kHz}$, and stored on computer (AxoScope software; Axon Instruments, Foster City, CA). Following recording, Neurobiotin was injected $(+0.5 \mathrm{nA}$ with $50 \%$ duty cycle, 3-10 $\mathrm{min}$ ).

The retina was fixed in $4 \%$ paraformaldehyde in $0.1 \mathrm{M}$ phosphate buffer (PB), $\mathrm{pH} 7.4$, for $45-60 \mathrm{~min}$ at room temperature and then stored in $\mathrm{PB}$ overnight at $4^{\circ} \mathrm{C}$. To visualize the filled cells, the retina was isolated and reacted for streptavidin-CY3 at room temperature: $1 \mathrm{hr}$ in $6 \%$ normal goat serum (NGS), $1 \%$ Triton X-100 (TX), and 0.5\% DMSO in $0.05 \mathrm{M}$ Tris-buffered saline (TBS); $2 \mathrm{hr}$ in $0.2 \%$ streptavidin-CY3, $3 \%$ NGS, $1 \%$ TX, and $0.5 \%$ DMSO in $0.05 \mathrm{M} \mathrm{TBS}$; and rinsed for $30 \mathrm{~min}$ in $0.05 \mathrm{M}$ TBS. The retina was mounted in Vectashield, and cells were visualized with fluorescence microscopy.

Stimuli. Cells were classified as ON or OFF center using spots and annuli, and then the nonlinear receptive field was probed using gratings. Sine wave or square wave gratings of various spatial frequencies drifted or contrast-reversed at $2 \mathrm{~Hz}$. Stimuli were defined in terms of Michelson contrast: $\left(I_{\max }-I_{\min }\right) /\left(I_{\max }+I_{\min }\right)$, where $I_{\max }$ and $I_{\min }$ are the peak and trough intensities. Thus, the mean intensity stayed constant over time, and stimulus intensity varied around the mean with a maximum possible contrast of $100 \%$. We programmed the stimuli in Matlab (MathWorks, Natick, MA), using extensions provided by the high-level Psychophysics Toolbox (Brainard, 1997) and the low-level Video Toolbox (Pelli, 1997).

The stimulus was displayed on a 1-inch-diameter computer monitor with green (P43) phosphor (Lucivid MR1-103; MicroBrightField, Colchester, VT), projected through the top port of the microscope and focused onto the retina with a $2.5 \times$ objective. The mean intensity of the stimulus was $28 \mathrm{nW} / \mathrm{mm}^{2}$ at $545 \mathrm{~nm}$ light. Given the peak sensitivity of M cones, which predominate in the guinea pig visual streak $(530 \mathrm{~nm})$ (Jacobs and Deegan, 1994; Rohlich et al., 1994), this translates to $\sim 10^{6}$ isomerizations per cone per second. The monitor resolution was $640 \times$ 480 pixels with $60 \mathrm{~Hz}$ vertical refresh; stimuli were confined to a square region of 430 pixels on a side ( $3.7 \mathrm{~mm}$ on the retina). The relationship between voltage and monitor intensity was linearized in the software with a lookup table.

We measured the optical line spread at the plane of the retina. A bright edge was stepped across a $200-\mu \mathrm{m}$-diameter aperture mounted on a radiometer (IL1400A; International Light Inc., Newburyport, MA). The measured relative intensity at each position was fit by the expected relative intensity convolved with a gaussian with SD of $19 \mu \mathrm{m}$ (full width at half height of $40 \mu \mathrm{m}$ ).

Data analysis. Data were analyzed with programs written in Matlab. Spikes were detected off-line by analyzing the first derivative of the membrane potential response and finding points above a threshold. Poststimulus time histograms were accumulated across 20 stimulus cycles (bin width of $16.7 \mathrm{msec}$ ). To analyze changes in the membrane potential, spikes were removed by linear interpolation of the voltage trace from 5 msec before each spike to $8-13$ msec after each spike. This did not affect the subsequent Fourier analysis at the low stimulus temporal frequency. The average membrane potential was analyzed across 20 stimulus cycles (Fig. 1C). To quantify the signal, we measured amplitude at the stimulus frequency, Fourier $\mathrm{F}_{1}$ component $(2 \mathrm{~Hz})$, and twice the stimulus frequency, Fourier $\mathrm{F}_{2}$ component $(4 \mathrm{~Hz})$.

\section{RESULTS}

Fifty ganglion cells were studied, mostly in the visual streak (Fig. $1 A)$. Somas were $15-25 \mu \mathrm{m}$ in diameter with monostratified dendritic fields spanning 350-700 $\mu \mathrm{m}$; the tracer-filled axons could be followed toward the optic disk (Fig. $1 B$ ). Most cells were OFF center $(n=42)$, depolarizing when a small spot dimmed over the dendritic field. The population included both "brisk" cells whose depolarizations peaked in 50-150 msec, and "sluggish" cells whose depolarizations peaked in 200-250 msec (Cleland and Levick, 1974). All cells exhibited nonlinear responses to contrast-reversing gratings (i.e., a dominant $\mathrm{F}_{2}$ response component), and so none were homologous to linear $\mathrm{X}$ cells in cat retina. Because drug effects were similar in brisk and sluggish cells, the results have been combined in the population analyses. 
A cell was considered healthy as long as the membrane potential $\left(E_{\mathrm{m}}\right)$ was more negative than $-45 \mathrm{mV}$ and stable. The average resting potential was $-54 \pm 8 \mathrm{mV}$ (mean $\pm \mathrm{SD}$ ), and it often held steady for $0.5-4 \mathrm{hr}$. Nearly half of the cells lasted for $>1 \mathrm{hr}$. Resting spike rates averaged $12 \pm 11$ spikes/sec. The most stable recordings gave slightly higher spontaneous rates $(15 \pm 7$ spikes/ sec; $n=11)$ and maximal evoked responses of $119 \pm 48$ spikes/ sec. The guinea pig ganglion cells in our experiments fired spontaneously at the same rate as cat $\mathrm{Y}$ cells and gave evoked responses of similar magnitude (Troy and Robson, 1992). This seemed remarkable given that the cat recordings were made extracellularly in the intact animal; whereas the present cells were penetrated by a sharp electrode in a flattened retina bathed in artificial medium.

\section{Linear and nonlinear responses are represented in the membrane potential}

Our first finding was that guinea pig retina contains ganglion cells that express both linear and nonlinear responses (Figs. 2-5). The linear response was evoked by a drifting grating, which strongly modulated the membrane potential at the drift rate, producing a large amplitude at the stimulus frequency (Fourier $\mathrm{F}_{1}$ component) (Figs. $1 C, 2$ ). The nonlinear response was evoked by a contrast-reversing grating, which strongly modulated the membrane potential at twice the reversal rate, producing a large amplitude at twice the stimulus frequency (Fourier $\mathrm{F}_{2}$ component) (Fig. 2). This distinction between the linear and nonlinear responses has been thoroughly described for Y cells and nonlinear W cells in cat (Hochstein and Shapley, 1976; Troy et al., 1989, 1995; Rowe and Cox, 1993) and for "Y-like" cells in monkey (Kaplan and Shapley, 1982).

The specific properties of the $\mathrm{F}_{1}$ and $\mathrm{F}_{2}$ response components observed in the spike train were clearly evident in the membrane potential. Thus, the $F_{1}$ component was sensitive to the spatial position of a contrast-reversing grating and was absent at certain positions ("null phases"); whereas the $\mathrm{F}_{2}$ component was similar at all grating positions (Fig. 3) (Hochstein and Shapley, 1976). We measured the ratio of the average $\mathrm{F}_{2}$ component to the maximal $\mathrm{F}_{1}$ component in response to a contrast-reversing grating of high spatial frequency at several grating positions $(n=12,2 \mathrm{ON}, 10$ $\mathrm{OFF}$ ). Across cells, the $\mathrm{F}_{2} / \mathrm{F}_{1}$ component ratio was similar for the membrane potential response (ratio, $2.0 \pm 1.0$ ) and the spike response (ratio, $2.2 \pm 1.4$ ). This ratio is similar to that reported for Y cells and Y-like cells (Enroth-Cugell and Robson, 1966; Hochstein and Shapley, 1976; Kaplan and Shapley, 1982).

The membrane potential's $\mathrm{F}_{1}$ response component was maximal to a coarse contrast-reversing grating (bar width approximately equal to dendritic field width); whereas the $\mathrm{F}_{2}$ response component was maximal to a fine contrast-reversing grating (approximately one-twentieth of the dendritic field width) (Figs. 3, 4) (Hochstein and Shapley, 1976). The membrane potential also displayed the expected relative $\mathrm{F}_{1}$ and $\mathrm{F}_{2}$ response components to both central and peripheral contrast-reversing gratings. Thus, the $\mathrm{F}_{1}$ component was maximal to a central, coarse stimulus; whereas the $\mathrm{F}_{2}$ component was maximal to a fine stimulus in both center and periphery (Fig. 5) (Derrington et al., 1979). Because all key features of the $F_{1}$ and $F_{2}$ response components are represented in the membrane potential, we could measure them when the ganglion cell spikes were blocked.
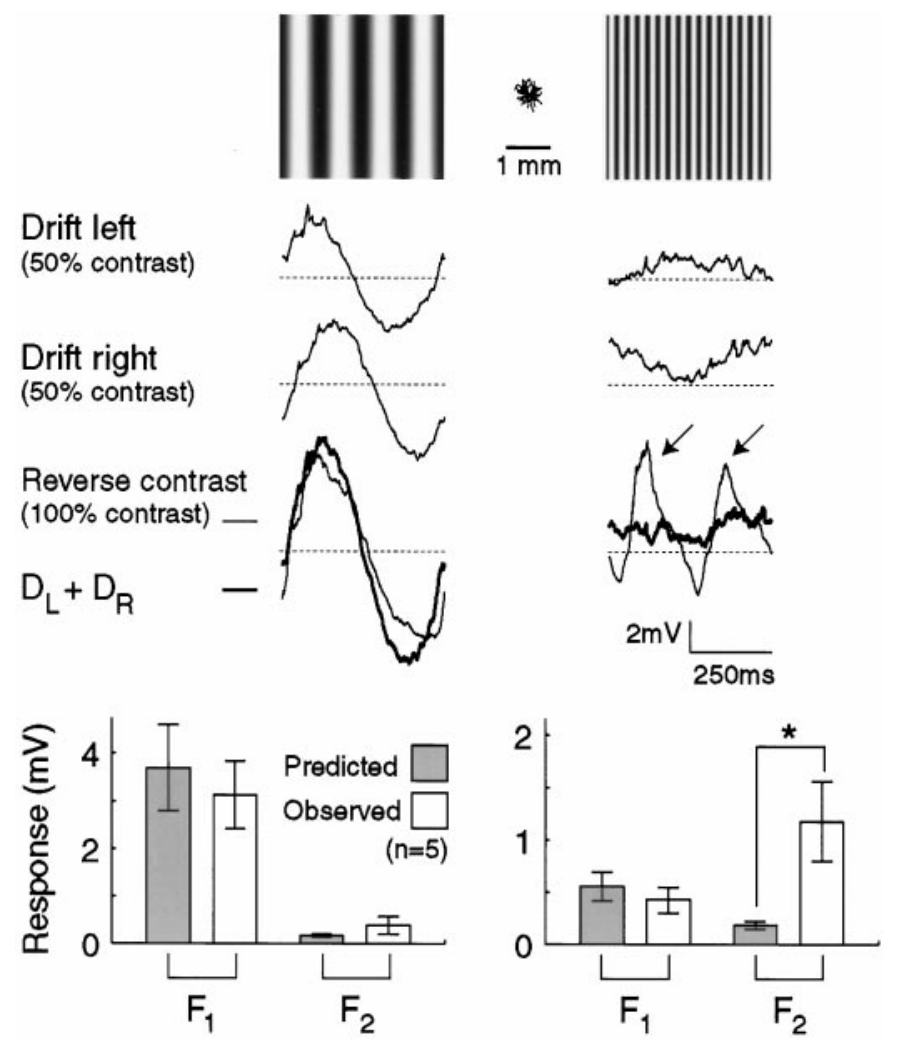

Figure 2. Frequency-doubled, nonlinear response emerges when a fine grating reverses contrast. Left column, OFF center cell depolarizes to the dark phase of a coarse grating drifted over its receptive field and hyperpolarizes to the bright phase. The response to drifting gratings includes a large Fourier component at the drift frequency ( $\mathrm{F}_{1}$ component). Combining gratings drifting leftward and rightward forms a stationary grating that reverses contrast (sine wave reversal). This contrast-reversing grating evokes an "observed" response (thin line), $10 \mathrm{mV}$ peak-to-peak, nearly as large as the "predicted" response, corresponding to the summed responses to the two drifting gratings $\left(D_{\mathrm{L}}+D_{\mathrm{R}}\right.$; thick line $)$. The difference is mostly caused by a small $\mathrm{F}_{2}$ response component that emerges to the contrast-reversing grating, calculable by Fourier analysis, but not obvious in the trace. Bar graph shows a good match between the predicted and observed $\mathrm{F}_{1}$ component and a slightly higher than predicted $\mathrm{F}_{2}$ component in response to a coarse, contrast-reversing grating. Right column, Fine drifting grating evokes a small response at the drift frequency. A contrast-reversing grating evokes a large response at twice the rate of contrast reversal (a large $\mathrm{F}_{2}$ component, arrows). The observed response is quite different from the predicted response. Bar graph shows that the observed $\mathrm{F}_{2}$ component in the response to a fine, contrastreversing grating was significantly greater than predicted $\left({ }^{*} p<0.05 ; t=\right.$ 2.84; one-tailed $t$ test; $\mathrm{df}=4$ ). The average $\mathrm{F}_{2}$ component in the response to a fine, contrast-reversing grating was just under half the amplitude of the average $\mathrm{F}_{1}$ component in the response to a coarse, contrast-reversing grating.

\section{Nonlinear response to a peripheral grating can be initially depolarizing or hyperpolarizing}

The nonlinear response measured in the spike train to a peripheral contrast-reversing grating was generally considered an excitatory response, i.e., firing above the background rate (Kruger and Fischer, 1973; Derrington et al., 1979) (but see Fischer et al., 1975; Watanabe and Tasaki, 1980). However, the responses measured in the membrane potential demonstrated two distinct patterns. As expected, some cells (14 of 41) initially depolarized 50-100 msec after each contrast reversal of a peripheral grating, and this increased spiking above the mean level (Fig. 6, left columns). However, most cells (27 of 41) initially hyperpolarized 

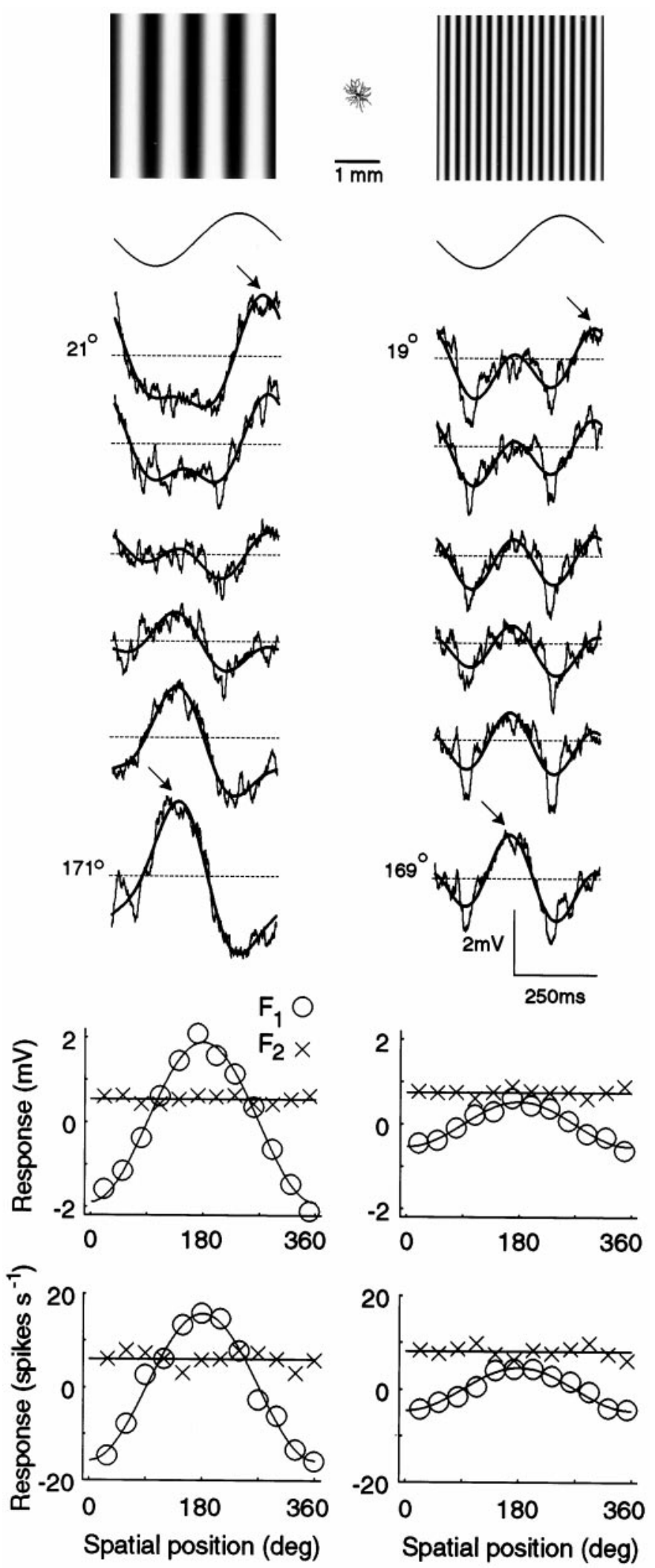

Figure 3. Nonlinear response is independent of grating position. Left column, Coarse grating reversed contrast and was presented at six positions, offset successively by $30^{\circ}$ (grating cycle is $360^{\circ}$ ). ON center cell's $\mathrm{F}_{1}$ response component was maximal at first and last positions (arrows). $\mathrm{F}_{2}$ response component was approximately equal at all positions but most apparent in middle traces where $\mathrm{F}_{1}$ component is small. Thick line shows for each trace the sine waves (summed after subtracting the mean)
A

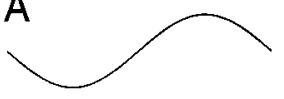

B
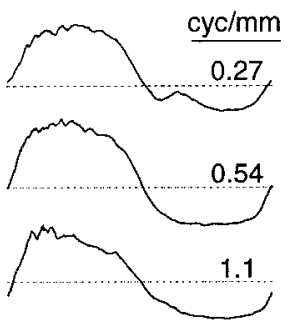

$\int 2.2$
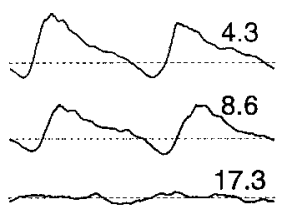

$5 \mathrm{mV}$

$250 \mathrm{~ms}$
$F_{1} O$

$\mathrm{F}_{2} \times$

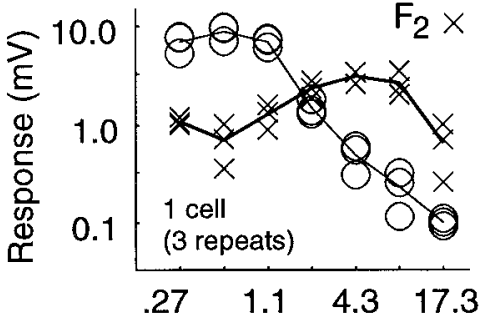

C

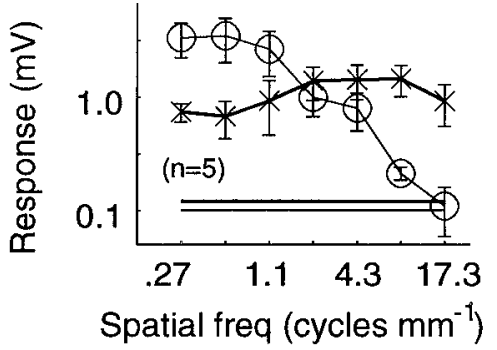

Figure 4. Linear and nonlinear responses are tuned reciprocally over a wide range of spatial frequencies. $A$, OFF center cell response to the coarse, contrast-reversing gratings had a large $F_{1}$ component and small $F_{2}$ component; response to fine gratings had a small $\mathrm{F}_{1}$ component and a large $\mathrm{F}_{2}$ component. $B$, Plot of $\mathrm{F}_{1}$ and $\mathrm{F}_{2}$ response components for cell in $A$. $C$, Same plot for the average response of five cells (error bars indicate SEM). Horizontal lines mark average noise levels for $\mathrm{F}_{1}$ component (thin) and $\mathrm{F}_{2}$ component (thick) measured in a baseline condition ( $0 \%$ contrast) at the same mean luminance.

with a sharp transient 50-100 msec after each contrast reversal that suppressed spiking. This was followed by depolarization that drove spiking above the mean rate (Fig. 6, right columns). This grouping, based on positive or negative changes following contrast reversal, necessarily divides the cells into two groups, but this separation may be meaningful because L-AP-4 affected the two cell groups differently (see below).

The two patterns of response to a peripheral contrast-reversing grating did not correspond to whether the ganglion cell was ON versus OFF center. For example, an OFF cell could display either one of the two response patterns (Fig. 6, top row). However, there was some relationship between the response to a peripheral grating and the time course of the center response. Thus, most OFF cells with an initially depolarizing response were sluggish (7of 9), whereas, most OFF cells with an initially hyperpolarizing response were brisk (14 of 20).

The nonlinear response measured to a central contrastreversing grating [500 $\mu \mathrm{m}$ outer diameter (OD)] was typically

corresponding to the $F_{1}$ and $F_{2}$ components. Graph shows $F_{1}$ and $F_{2}$ component amplitudes as a function of grating position [each trace above contributes two points at the recorded position (e.g., $21^{\circ}$ ) and by reanalyzing after shifting by one half-cycle (e.g., $\left.\left.201^{\circ}\right)\right] . \mathrm{F}_{1}$ component reaches a maximum amplitude of $2 \mathrm{mV}$ (or 15 spikes) and modulates with spatial position, whereas $\mathrm{F}_{2}$ component is $\sim 0.5 \mathrm{mV}$ (or 6 spikes) amplitude and invariant with spatial position. Fitted functions are a negative cosine $\left(\mathrm{F}_{1}\right.$ component) and a line ( $\mathrm{F}_{2}$ component). Right column, To a fine grating, $\mathrm{F}_{2}$ response component was stronger than $\mathrm{F}_{1}$ component at all spatial positions. A similar result was observed in 11 additional cells ( $1 \mathrm{ON}, 10$ OFF; see Results). 

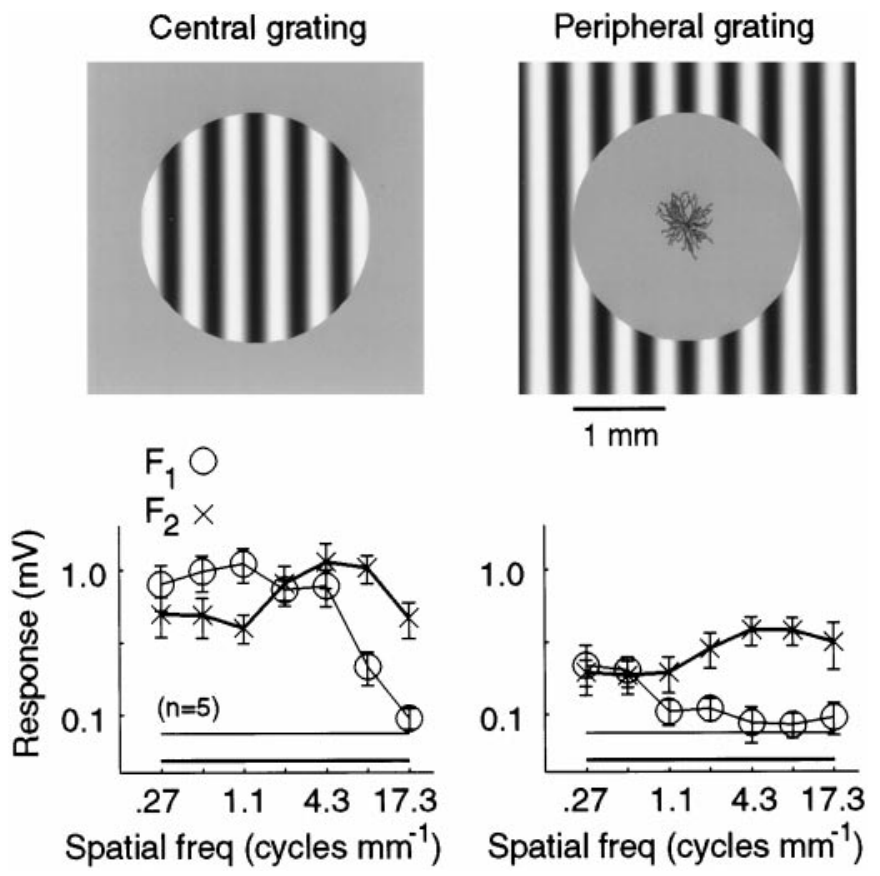

Figure 5. Nonlinear response evoked by a peripheral, contrast-reversing grating far beyond the ganglion cell's dendritic field has lower amplitude but the same spatial tuning as nonlinear response evoked by a central grating. Central grating was $2.3 \mathrm{~mm}$ OD; peripheral grating was presented as an annulus with $2.5 \mathrm{~mm}$ ID. Other conventions are the same as Figure $4 C$.

biphasic. The response could be initially hyperpolarizing then depolarizing, or vice versa, and its waveform varied markedly across cells. A qualitative grouping suggested four to five types of waveform $(n=15)$, but a detailed classification remains to be done. For the current study, however, the drug effects on the nonlinear response to a central grating were similar across cells, and so they have been combined in the population analyses.

\section{Evidence that a single class of cone bipolar cell can generate the nonlinear response}

The ganglion cells studied here are monostratified, branching in either the inner or outer strata of the inner plexiform layer. Thus, each receives synapses from a single class of cone bipolar cell (ON or OFF), which can generate the ganglion cell's classical center/surround response (Wässle and Boycott, 1991; Sterling, 1998). A center spot (bright for ON ganglion cells, dim for OFF ganglion cells) would increase the bipolar cell's glutamate release, whereas an annulus (bright for ON ganglion cells, dim for OFF ganglion cells) would decrease the bipolar cell's glutamate release. A monostratified amacrine cell's contribution to the surround response would also be driven by the same class of bipolar cell. Physiological evidence for this model comes from measurements of ganglion cell center/surround responses while blocking ON bipolar responses with L-AP-4 (Shiells et al., 1981; Slaughter and Miller, 1981). Both the center response to a spot and the surround response to an annulus were blocked by L-AP-4 in ON ganglion cells but not in OFF ganglion cells (Schiller, 1982; Knapp and Mistler, 1983; Bolz et al., 1984).

Might the ganglion cell's nonlinear response also arise from a single class of bipolar cell (ON or OFF)? To investigate this, we presented two sets of bars that reversed contrast over time (i.e., black $\leftarrow \rightarrow$ white). Each set of bars occupied half the area of the receptive field center, and they were spatially complementary. Combined in-phase, they created a spot and combined out-ofphase, they created a contrast-reversing grating (Fig. 7A). The responses to the two sets of bars when summed in-phase matched the shape of the response to a spot and nearly matched the amplitude. Presumably, the match arises because both a spot and the complementary sets of bars excite the same OFF bipolar cells. The responses to the two sets of bars when summed out-of-phase matched the shape of the response to a contrast-reversing grating and most of the amplitude. In short, over the dendritic field, both the center response to the spot and the nonlinear response to the contrast-reversing grating could be predicted simply by summing the responses elicited by the same sets of bars.

We performed a similar experiment in the periphery. Two complementary sets of contrast-reversing bars were presented that combined in-phase to create an annulus and combined outof-phase to create a peripheral contrast-reversing grating (Fig. $7 B)$. The responses to the two sets of bars when summed in-phase matched the shape of the response to an annulus. Presumably, the match arises because both an annulus and the complementary sets of bars inhibit the same OFF bipolar cells. The responses to the two sets of bars when summed out-of-phase matched the shape of the response to a peripheral contrast-reversing grating. In short, beyond the dendritic field, both the surround response to the annulus and the nonlinear response to the contrast-reversing grating could be predicted simply by summing the responses elicited by the same sets of bars.

This result, that the summation of bar responses could predict both center/surround responses to a spot/annulus and nonlinear responses to a grating in both center and periphery held for all cells studied (seven OFF, one ON), including both sluggish and brisk (Fig. 7). That the same component responses, added inphase or out-of-phase, could predict both center/surround and nonlinear responses, suggested that the input driving the two mechanisms is the same. Because the center/surround is driven by a single class of bipolar cell (ON or OFF), it follows that the nonlinear mechanism is driven by the same single class of bipolar cell.

\section{L-AP-4 does not reduce the nonlinear response in OFF ganglion cells}

If the nonlinear response in an OFF center ganglion cell were driven solely by OFF bipolar cells, the response should be undiminished when $\mathrm{ON}$ bipolar cell light responses are blocked by L-AP-4 (Shiells et al., 1981; Slaughter and Miller, 1981; Nawy and Jahr, 1990). To test this, we applied L-AP-4 (10 $\mu \mathrm{M}, n=2 ; 40 \mu \mathrm{M}$, $n=12)$. An ON ganglion cell's light responses were blocked in 20 sec, indicating full block of ON cone bipolar cells (Fig. 8A). In $\mathrm{OFF}$ ganglion cells, the resting potential was unchanged (initial, $-51 \pm 9 \mathrm{mV}$; L-AP-4, $-50 \pm 11 \mathrm{mV} ; n=14$ ), but to a central contrast-reversing grating, the average $\mathrm{F}_{2}$ response component increased by fourfold $(4.2 \pm 2.9)$ (Fig. 8$)$. When the drug was washed out, the $\mathrm{F}_{2}$ response component declined to $2.1 \pm 1.1$ times the initial level (Fig. $8 B$ ). To a peripheral contrast-reversing grating, the average $\mathrm{F}_{2}$ response component in cells with an initially hyperpolarizing response increased in the presence of L-AP-4 by fourfold at the three highest contrasts $(4.3 \pm 3.1$ times initial) (Fig. 9). To the same stimulus, the average $F_{2}$ response component in cells with initially depolarizing responses decreased $\sim 25 \%$ in the presence of L-AP-4 at the three highest contrasts $(0.75 \pm 0.76$ times wash) (Fig. 9), but responses were significantly lower only at 12.5 and $25 \%$ contrast $(t=2.47$ and 

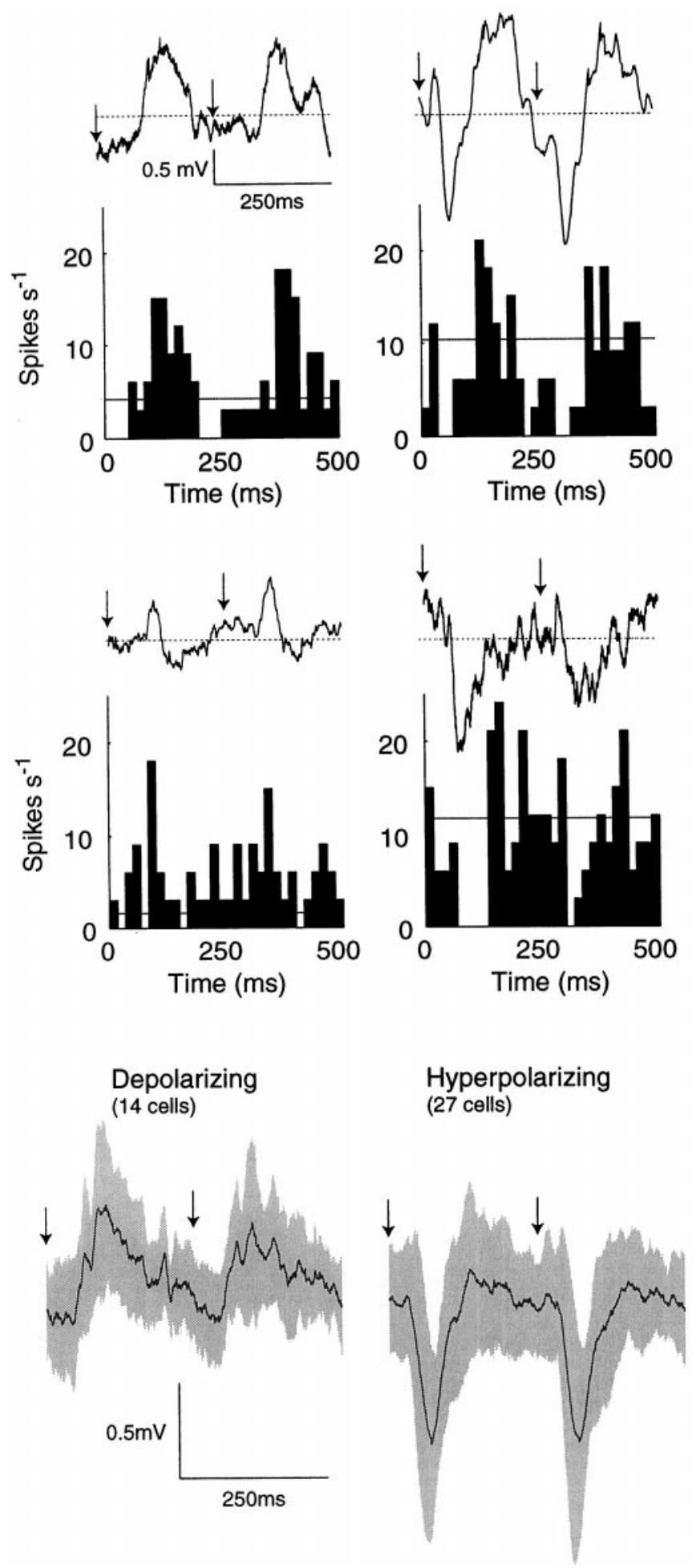

Figure 6. Initial response to a peripheral, contrast-reversing grating can be either depolarizing or hyperpolarizing. Left column, Certain cells, both OFF center (top) and ON center (middle), respond to each square wave reversal (arrows) of a peripheral grating with a transient depolarization and a burst of spikes above the mean rate (horizontal line). Mean response (dark trace) $\pm \mathrm{SD}$ (gray regions) for two ON and 12 OFF cells is shown (bottom). Right column, Other ganglion cells, both OFF (top) and ON (middle), responded to each square wave reversal (arrows) with a transient hyperpolarization and a pause in spiking followed by a burst in spiking above the mean rate. The initially hyperpolarizing response had a shorter latency and faster rise. Mean \pm SD response for five $\mathrm{ON}$ and 22 OFF cells is shown (bottom).
2.51; both $p<0.05$; one-tailed $t$ test; $\mathrm{df}=4)$. In these cells, the $\mathrm{F}_{2}$ component in the response to a central grating was not affected by L-AP-4.

On the whole, the nonlinear response in OFF ganglion cells is not blocked by L-AR-4's blocking of ON bipolar cells. For most cells and in most conditions, the nonlinear response is enhanced, possibly because of a general reduction of inhibition attributable to L-AP-4 effects on type III metabotropic glutamate receptors (mGluR) that distribute widely on amacrine processes (Hartveit et al., 1995; Koulen et al., 1996). This agreement between the bar summation experiment and the L-AP-4 effects suggests that nonlinear responses arise from a single class of bipolar cell.

In those cells with an initially depolarizing response to a peripheral contrast-reversing grating, L-AP-4 significantly reduced responses at low contrast. This might suggest that $\mathrm{ON}$ bipolar cells contribute to these responses at low contrast. However, it seems more plausible that this effect could also arise from the effect of L-AP-4 on amacrine cell type III mGluRs. In Figure 7, both cells displayed a depolarizing response to a peripheral grating, which could be predicted in the bar summation experiment. Therefore, it seems most likely that, even in these cells, the nonlinear response to a peripheral grating is driven by the same single class of bipolar cells that drives the center/surround.

\section{Nonlinear response to a peripheral grating requires action potentials}

The nonlinear response to a peripheral, contrast-reversing grating is relayed to a ganglion cell over more than a millimeter. To test whether action potentials are required, we evoked this nonlinear response while applying TTX (100 nM). Approximately 20 sec after TTX reached the retina, spiking ceased in the ganglion cell. Although the resting potential changed only slightly (initial, $-57 \pm 9 \mathrm{mV} ;$ TTX, $-60 \pm 8 \mathrm{mV} ; n=15)$, the $\mathrm{F}_{2}$ response component was abolished. This was true both in cells with initially hyperpolarizing and initially depolarizing responses (Fig. 10). In the presence of TTX, $F_{2}$ response components at the three highest contrasts decreased to $0.28 \pm 0.49$ times the initial level and were indistinguishable from noise ( $0 \%$ contrast response) (Fig. 10). After $\sim 5 \mathrm{~min}$ of wash, spiking returned, and both the resting potential $(-57 \pm 12 \mathrm{mV} ; n=13)$ and the response to the peripheral grating returned to initial levels. After TTX washed out, $\mathrm{F}_{2}$ response components at the three highest contrasts returned to $1.4 \pm 1.1$ times the initial level and were clearly above the noise (Fig. 10).

We considered whether TTX abolished the response to a peripheral grating by blocking spikes in the recorded ganglion cell or spikes in retinal interneurons. To test this, we included lidocaine $N$-ethyl bromide (QX-314; 25-50 mM) in the electrode to block spikes from inside the recorded ganglion cell. The response to a peripheral grating persisted but was then abolished by TTX (Fig. 10B). Thus, lateral relay of the nonlinear response from the periphery requires action potentials in retinal interneurons.

TTX did not abolish but rather increased the response to a central contrast-reversing grating $(n=2)$ (Fig. 11A). Because TTX abolished the response to a peripheral grating and enhanced the response to a central grating by an equal amount, the response to simultaneous stimulation by a full-field grating was primarily unaffected (Fig. $11 B$ ). The $\mathrm{F}_{2}$ response component increased to $1.4 \pm 1.4$ times the initial level in the presence of TTX and remained at $1.6 \pm 1.5$ times the initial level during the wash. The $F_{1}$ response component to these stimuli was small 

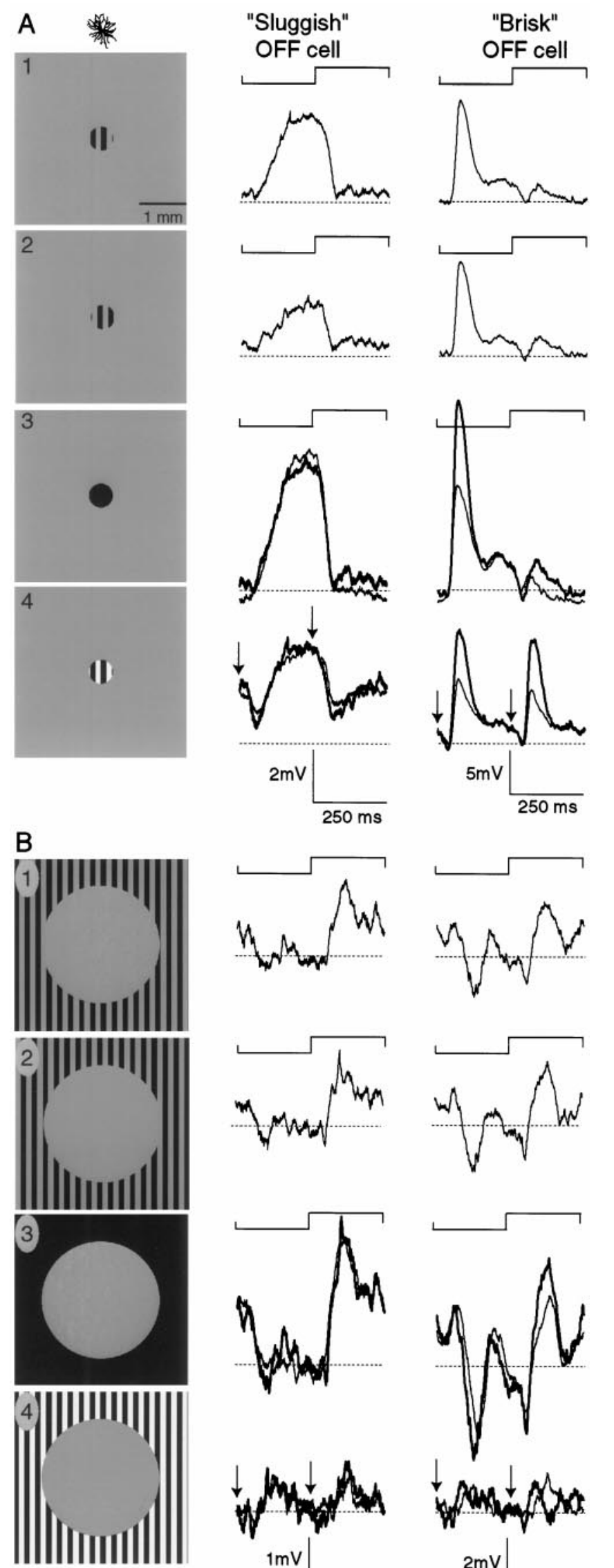
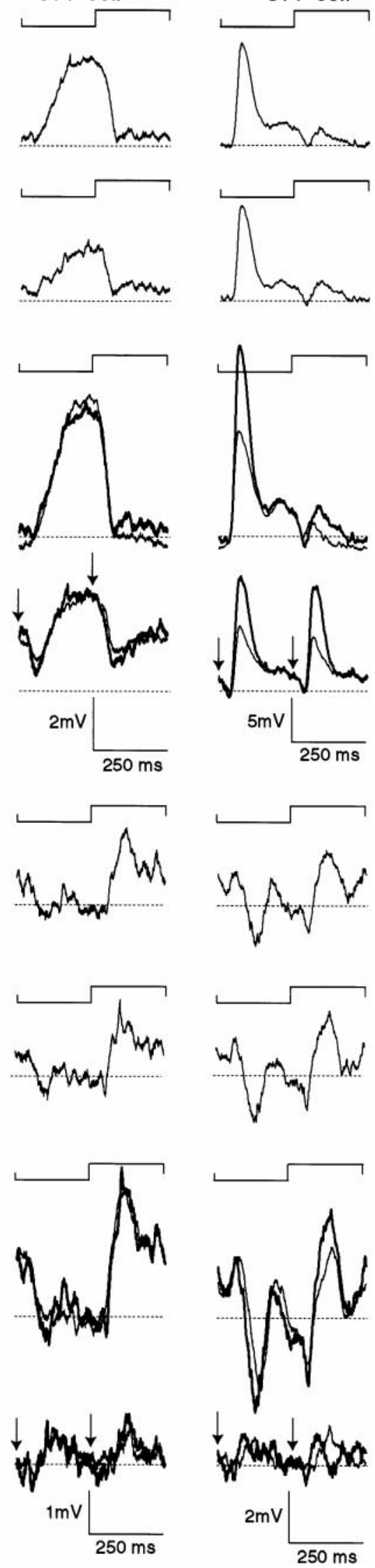

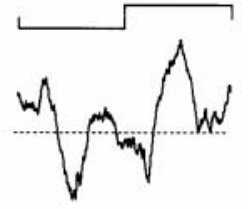

because the grating was fine, but it did also increase to $1.3 \pm 1.2$ times the initial level in the presence of TTX and remained at $1.4 \pm 1.2$ times the initial level during the wash $(n=9)$.

\section{Nonlinear response sums linearly at the ganglion cell}

The $\mathrm{F}_{2}$ response component to a contrast-reversing grating in the receptive field center was much stronger than the $\mathrm{F}_{2}$ response component to the same grating in the periphery (Fig. 12A). However, the response to a full-field grating was less than the sum of the response amplitudes to the gratings presented in concentric rings (Fig. 12A). This was because the responses were slightly out-of-phase. When responses were summed (taking into account phase, as well as amplitude), the result equaled the response to a full-field grating. This result, shown for a particular cell in Figure $12 B$, was true for most cells and can be seen in the average response of the population (Fig. 12C). Thus, spatial summation of the ganglion cell's nonlinear responses is linear.

\section{DISCUSSION}

We can now address the questions raised in the introductory remarks concerning the ganglion cell's nonlinear receptive field: how the subunit rectifies, how its signal travels millimeters across the retina, and how signals from multiple subunits combine at the ganglion cell.

\section{Model for the nonlinear circuit}

Figure 13 suggests a working model for the nonlinear receptive field. When a grating reverses contrast, cones under a dimming bar depolarize, and cones under a brightening bar hyperpolarize. Consequently, an OFF bipolar cell under the dimming bar releases more transmitter, and an OFF bipolar cell under the brightening bar releases less transmitter. A wide-field amacrine cell costratifying with the OFF bipolar synaptic terminals is depolarized by the first bipolar cell but not equivalently hyperpolarized by the second bipolar cell. This nonlinearity is assumed to arise at the bipolar-amacrine synapse (see below). The nonlinearity is then transmitted via the spiking amacrine cell to the ganglion cell and/or its presynaptic bipolar cell. The spiking amacrine cell probably releases GABA (Vaney, 1990) and would

Figure 7. Center/surround and nonlinear responses arise from the same bipolar pathway. $A_{1}$, The bars, presented over half of the receptive field center, reversed from black to white repeatedly, while the rest of the field remained gray. OFF ganglion cells depolarize at dark onset. This represents half of the classical center response. $A_{2}$, Same bars over the complementary regions of the center also evoke half of the center response. $A_{3}$, Both sets of bars $\left(A_{1}+A_{2}\right)$ when combined form a dark spot over the entire receptive field center. OFF cells strongly depolarize at dark onset (thin trace). This represents the entire center response. This response closely matches the summed responses to the bar stimuli (thick trace). The match is worse for the brisk cell, probably because of a summation property of the cell, such as a saturating nonlinearity, that limited the amplitude of the measured response. $A_{4}$, When $A_{2}$ bars are phase-shifted in time by $180^{\circ}$ (i.e., they start off bright instead of dark) and added to the $A_{1}$ bars, they form a contrast-reversing grating. OFF cells depolarize (thin traces) at each contrast reversal (arrows mark square wave reversal). When the $A_{2}$ response is phase-shifted in time by $180^{\circ}$ and added to the $A_{1}$ response, the sum (thick traces) closely matches the frequency-doubled response to the contrast-reversing grating. The center response to the spot is driven by a single class of cone bipolar cells (OFF bipolar cells, see Results). Because the same component responses to the bars predicted both the center response to the spot and the nonlinear response to the contrast-reversing grating, they are probably both driven by the same single class of bipolar cells (OFF bipolars). $B_{1}-B_{4}$, Same design as for $A$, but stimuli were restricted to the far periphery. Responses to stimuli $B_{1}$ and $B_{2}$ predicted the responses to stimuli $B_{3}$ and $B_{4}$. 


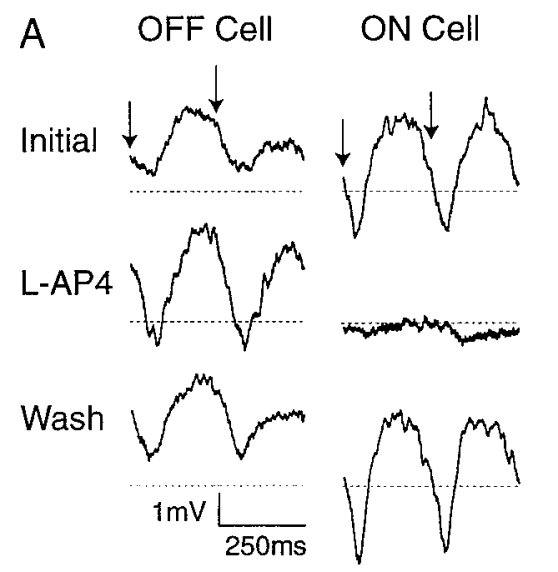

B OFF Cells $(n=9)$

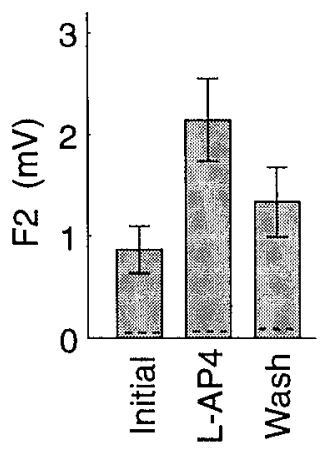

Figure 8. Nonlinear response in OFF ganglion cells to a central grating depends only on OFF bipolar pathway. $A$, Nonlinear response of an OFF ganglion cell to a central, contrast-reversing grating remained and was enhanced when ON bipolar cell light responses were blocked with $40 \mu \mathrm{M}$ L-AP-4 (arrows mark square wave contrast reversal). Nonlinear response of an ON ganglion cell was abolished. $B$, On average, $10-40 \mu \mathrm{M}$ L-AP-4 enhanced the $\mathrm{F}_{2}$ response component in OFF ganglion cells. Error bars indicate SEM; dashed lines indicate $\mathrm{F}_{2}$ component noise level recorded in a baseline condition at the same mean luminance ( $0 \%$ contrast).

thus initially hyperpolarize the ganglion cell at each contrast reversal. A similar mechanism could explain the initially depolarizing response to a peripheral grating if a local, inhibitory amacrine synapse were interposed between the spiking amacrine cell and the ganglion cell. The model would work equally well for ON ganglion cells driven by ON bipolar and amacrine cells.

This model implies that the fine subunits comprising the nonlinear receptive field correspond to the bipolar cell receptive field (Victor and Shapley, 1979b). The subunits resolve a grating at least 10-fold finer than the ganglion cell dendritic field (Figs. 4, 5). Each subunit would be $\sim 50 \mu \mathrm{m}$ in diameter, approximately the size of a bipolar cell receptive field center (Nelson and Kolb, 1983; Cohen and Sterling, 1992; Sterling, 1998). Also, the subunit's extent, like that of the bipolar cell center, is approximately constant with eccentricity (Figs. 4, 5) (Derrington et al., 1979). Finally, the same bipolar cell that drives the nonlinear subunit apparently also drives the classical center/surround. This is supported by Figure 7, which shows that the same component responses can predict both center/surround and nonlinear receptive field responses.

The subunit's underlying nonlinearity might well arise at the synaptic output of a specific category of cone bipolar cell (Figs. 8, 9). An OFF bipolar cell of this category would strongly increase its transmitter release to light offset (sluggishly or briskly) and weakly decrease transmitter release to light onset. This asymmetry is equivalent to "half-wave rectification." When a ganglion cell sums two such responses out-of-phase, it gives a characteristic frequency-doubled response (Fig. 7). The cat $b_{1}$ bipolar cell, presynaptic to the $\mathrm{Y}$ cell, provides an example of this behavior. Its release rate is low during steady light ( $\sim 1$ vesicle per synapse/ $\mathrm{sec}$ ), so light onset can evoke a large increment in transmitter release, but because of the low sustained rate, light offset cannot cause a comparable decrement (Freed, 1993; M. Freed, unpublished observations). Alternatively, the proposed mechanism of half-wave rectification via low basal release could apply to elements downstream from the bipolar cell.

Signals from the periphery of the nonlinear receptive field
A $\underset{\text { (Hyperpolarizing) }}{\text { OFF Cell }}$
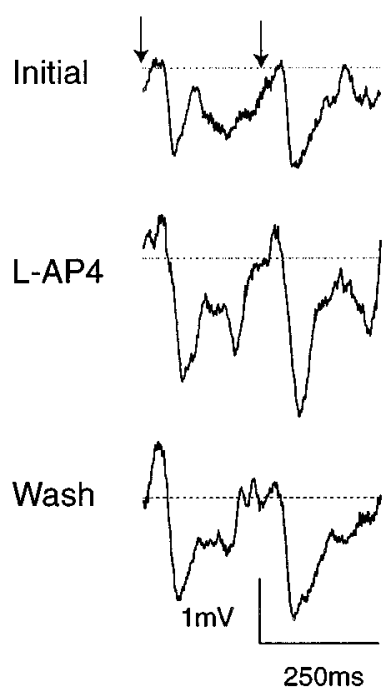

OFF Cells

(Hyperpolarizing, $n=5$ )
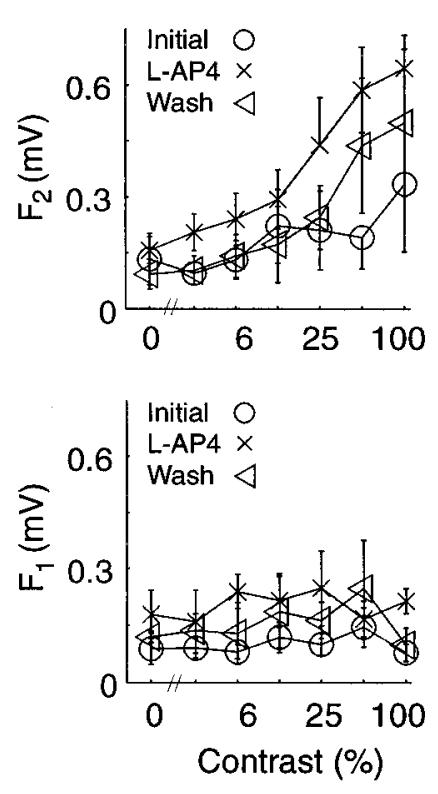

B
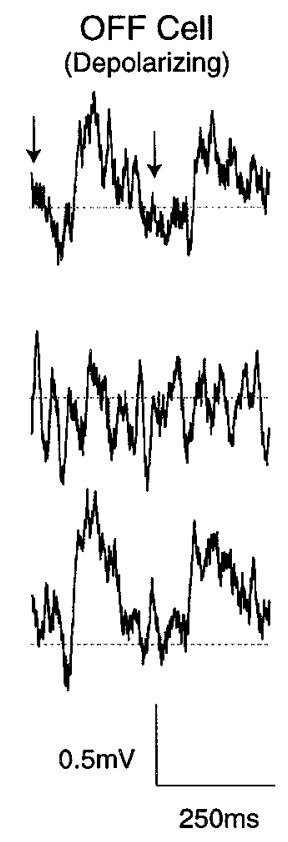

OFF Cells

(Depolarizing, $n=5$ )
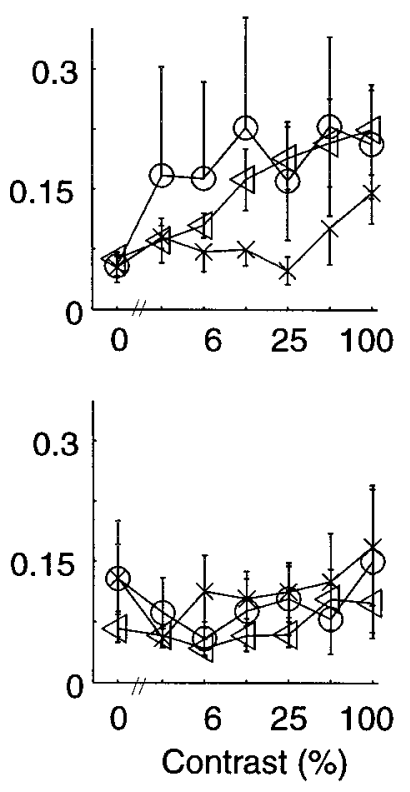

Figure 9. Nonlinear response in OFF ganglion cells to a peripheral grating depends only on OFF bipolar pathway. $A$, In response to a peripheral, contrast-reversing grating (50\% contrast), a cell's initially hyperpolarizing response increased with L-AP-4 (arrows mark square wave reversal). Line graph shows that, on average $( \pm S E M)$, the $F_{2}$ response component in OFF cells with an initially hyperpolarizing response increased with L-AP-4, whereas the $\mathrm{F}_{1}$ component was unaffected. (Wash response recorded in 4 of 5 cells.) $B$, In response to a peripheral, contrast-reversing grating (50\% contrast), a cell's initially depolarizing response was abolished by L-AP-4 but returned during the wash. On average, the $\mathrm{F}_{2}$ response component in OFF cells with an initially depolarizing response decreased with L-AP-4, especially at low contrasts, suggesting possible effects on group III mGluRs on amacrine cells (see Results), whereas the $F_{1}$ response components were unaffected. (Initial response recorded in 3 of 5 cells.) Wash recordings were taken $6 \pm 2$ min after L-AP-4 was removed from the bath. 


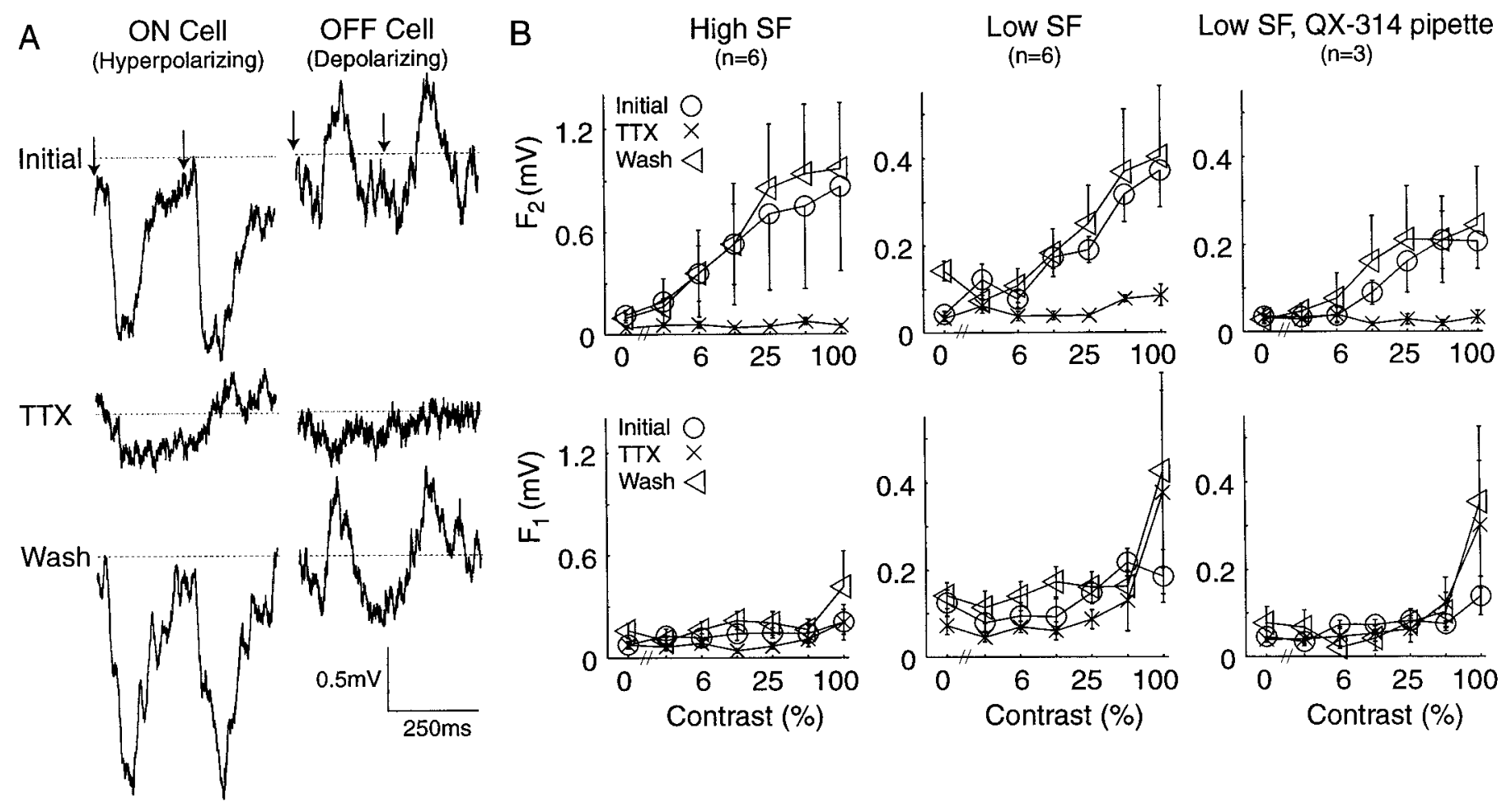

Figure 10. Nonlinear response to a peripheral grating is eliminated by tetrodotoxin. $A$, In response to a peripheral, contrast-reversing grating, both a cell with an initially hyperpolarizing response and a cell with an initially depolarizing response had their responses abolished by 100 nM TTX (arrows mark square wave reversal). $B$, In response to a peripheral, contrast-reversing grating, both the strongest $\mathrm{F}_{2}$ components to a fine grating (High $S F$ ) and more modest responses to a coarse grating (Low $S F$ ) were abolished by TTX. When QX-314 was included in the pipette to block ganglion cell voltage-dependent sodium currents from the inside, the $\mathrm{F}_{2}$ response components remained but were subsequently abolished by TTX. $\mathrm{F}_{1}$ response components to the coarse grating increased and remained high during the TTX washout. Wash recordings were taken $15 \pm 7$ min after TTX was removed from the bath.

almost certainly reach the ganglion cell via a spiking interneuron. These signals travel at $\sim 0.34 \mathrm{~m} / \mathrm{sec}$, consistent with a spiking mechanism (Fischer et al., 1975; Derrington et al., 1979). Furthermore, the nonlinear response to a peripheral grating was abolished by tetrodotoxin (Fig. 10). These signals could be transmitted by an amacrine cell with multiple axons that extend for millimeters across the retina (Vaney et al., 1988; Dacey, 1989; Famiglietti, 1992a-c; Bloomfield, 1996; Freed et al., 1996; Stafford and Dacey, 1997). The guinea pig retina contains such amacrine cells with axons that extend up to $3 \mathrm{~mm}$ (Kao et al., 1999).

It is notable that the nonlinear receptive field, which extends for millimeters, is summed linearly at the ganglion cell (Fig. 12). This linear summation was not tested previously over such a wide region, but it is consistent with the original model of the nonlinear subunits (Hochstein and Shapley, 1976; Victor and Shapley, 1979b). It implies that the subunits operate independently and therefore may not interact synaptically.

\section{Does the nonlinear receptive field extend beyond the classical surround?}

In cat Y cells, the nonlinear receptive field was initially described as extending beyond the classical surround (Fischer et al., 1975; Derrington et al., 1979). However, it now appears that the surround extends further than previously thought, $\sim 2 \mathrm{~mm}$ retinal distance from the receptive field center (Troy et al., 1993). Thus, in the cat Y cell, the nonlinear receptive field, and the classical surround are primarily coextensive. In the present experiment, the nonlinear receptive field in brisk and sluggish guinea pig

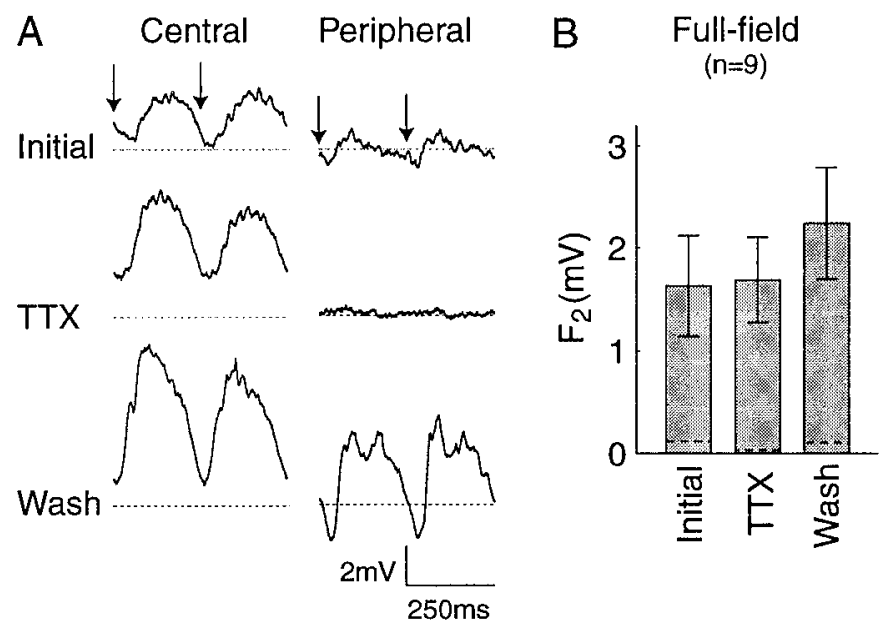

Figure 11. Nonlinear response to a central grating is not eliminated by tetrodotoxin. $A$, In response to a central, contrast-reversing grating, an OFF cell's nonlinear response not only survived $100 \mathrm{~nm}$ TTX, it actually grew larger during the application and washout. The response to a peripheral contrast-reversing grating was completely abolished by TTX but recovered promptly during washout. $B$, In response to a full-field contrast-reversing grating, the average $\mathrm{F}_{2}$ component was unaffected by TTX, presumably because, as the response to peripheral stimulation was attenuated, the response to central stimulation was enhanced. 

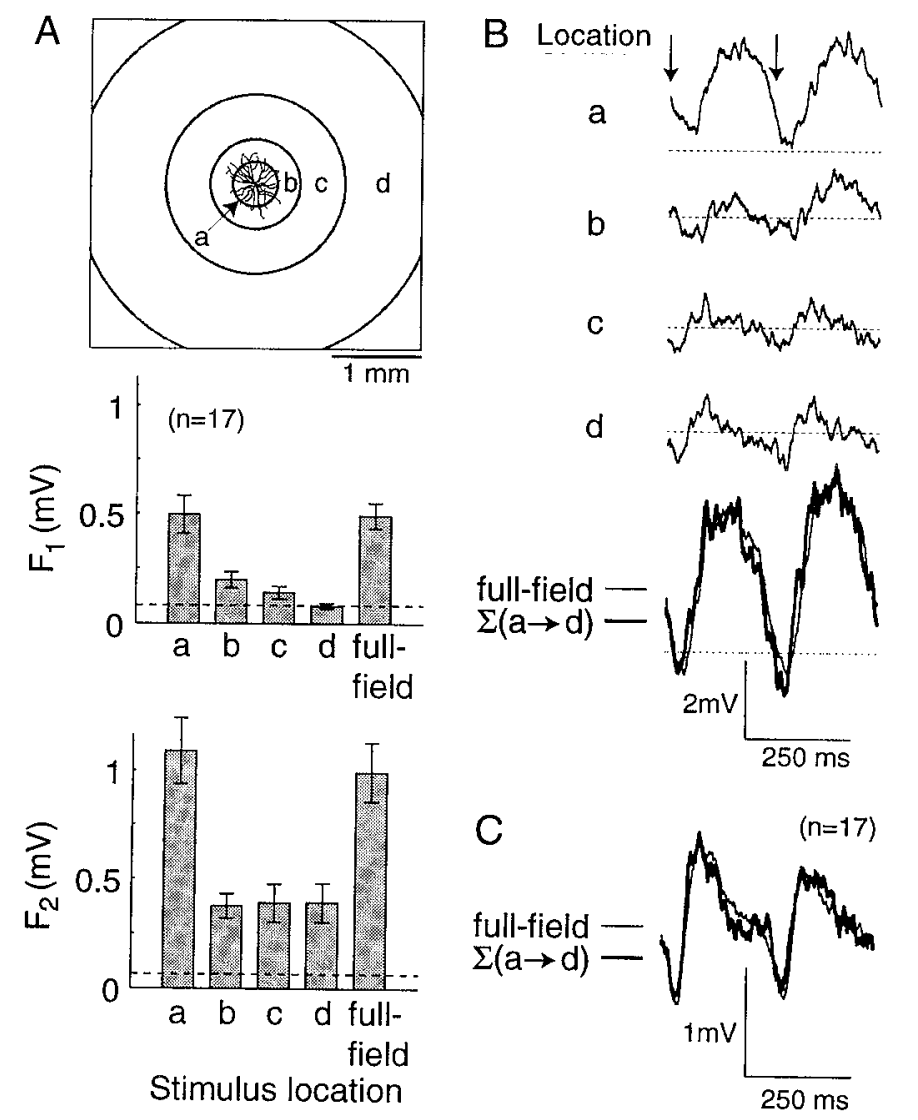

Figure 12. Nonlinear response sums linearly at the ganglion cell. $A$, Fine grating reversed contrast in regions $a-d$, or at all locations ( full field). On average, the $\mathrm{F}_{2}$ response component (mean \pm SEM) was strongest for $a$ but always remained well above the noise (horizontal line). $\mathrm{F}_{1}$ response component was strongest for $a$ and then fell toward the noise. $B$, Responses in an OFF cell to gratings at each location were summed to predict the response to a full-field grating. The close correspondence between the two traces demonstrates that the nonlinear response sums linearly across the receptive field. $C$, Across all cells ( 1 ON, 16 OFF), average responses to gratings at each location were summed to predict the average response to a full-field grating. The close correspondence between the traces demonstrates that, on average, the nonlinear response sums linearly across the receptive field.

ganglion cells was also coextensive with the classical surround (Fig. 7B).

\section{Most ganglion cell types express a nonlinear receptive field}

The nonlinear receptive field seems to be expressed by most ganglion cell types in all mammalian species. In guinea pig, all cells we have studied so far ( $\sim 7$ wide-field types) express a nonlinear receptive field (Sterling et al., 1999). In cat retina, Y and $\mathrm{W}$ cells express a nonlinear receptive field (Hochstein and Shapley, 1976; Troy et al., 1989; Rowe and Cox, 1993; Pu et al., 1994; Troy et al., 1995), and even X cells, generally considered to be linear, express nonlinear responses from the periphery (Barlow et al., 1977; Hamasaki and Maguire, 1985). Furthermore, nonlinear receptive fields are expressed by ganglion cell types in rabbit (Caldwell and Daw, 1978; Watanabe and Tasaki, 1980), mouse (Stone and Pinto, 1993), and monkey (Kruger et al., 1975; Kaplan and Shapley, 1982). In monkey retina, there may be certain cell types that are completely linear and do not, under any condition, express a nonlinear receptive field (Kaplan and Shap-

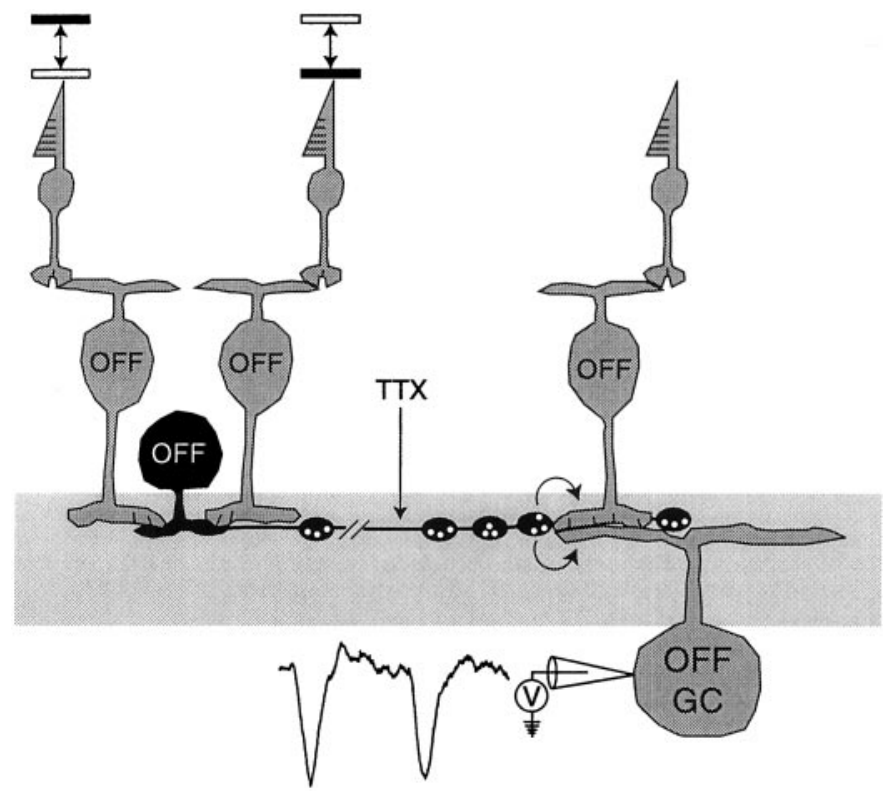

Figure 13. Circuit diagram to explain the origin of the initially hyperpolarizing response to a peripheral, contrast-reversing grating. When a grating reverses contrast in the periphery, it evokes asynchronous responses in adjacent cones and thus in their postsynaptic OFF bipolar cells. The latter release transmitter asynchronously onto an OFF wide-field spiking amacrine cell. Assuming that the nonlinearity arises at the bipolar-amacrine synapse (see Discussion), it is then transmitted via the spiking amacrine cell to the ganglion cell and/or its presynaptic bipolar cell. The spiking amacrine cell releases an inhibitory transmitter, such as GABA, and hyperpolarizes the ganglion cell at each contrast reversal, creating the characteristic nonlinear response.

ley, 1982; Benardete et al., 1992). However, at least one class of neurons in the magnocellular layer of the lateral geniculate nucleus has a local nonlinear receptive field (Kaplan and Shapley, 1982; Benardete et al., 1992), and a larger percentage may show a peripheral nonlinear receptive field (Kruger, 1977).

\section{Function of the nonlinear receptive field for vision}

Although nonlinear responses were observed long ago, they were described as mere "effects" (the "McIlwain," "periphery," or "shift" effect), and only later were these related to the Y cell nonlinear subunit (McIlwain, 1964, 1966; Fischer et al., 1975; Derrington et al., 1979). Yet we are impressed that these responses are not oddities but reflect powerful circuits for computing contrast magnitude over a wide region. The ganglion cell might use this information to tune its linear receptive field. For example, when the nonlinear receptive field is stimulated continuously with a fine, drifting grating, the gain of the linear center is sharply reduced (Werblin, 1972; Caldwell and Daw, 1978; Enroth-Cugell and Jakiela, 1980). Alternatively, when the peripheral nonlinear receptive field is stimulated, the linear center of certain cells may be enhanced (McIlwain, 1964). This gain control might serve psychophysical "masking" whereby the ability to detect a small spot is modulated by surrounding stimuli (Derrington, 1984; He and Loop, 1990; Fuhr and Kuyk, 1998). However, the nonlinear receptive field may have other functions. For example, the nonlinear receptive field is still expressed by geniculate neurons, so it must be relayed to cortex where it might carry a message complementary to that of the linear receptive field (So and Shapley, 1979; cf. Spitzer and Hochstein, 1987).

It is a matter of great current interest that a nonlinear mech- 
anism in the cortex computes "second order" contrast boundaries. In a scene where average luminance stays constant over space, object boundaries are determined by changes in local contrast on a fine scale. Such contrast boundaries are invisible to a linear mechanism that computes only "first order" luminance boundaries on a coarse scale (Mareschal and Baker, 1998, 1999). Shown psychophysically, this nonlinear mechanism was composed of fine subunits and insensitive to orientation (McGraw et al., 1999). Most studies have assumed a cortical mechanism. However, the ganglion cell nonlinear receptive field might also contribute to this visual computation.

\section{REFERENCES}

Barlow HB (1953) Summation and inhibition in the frog's retina. J Physiol (Lond) 119:69-88.

Barlow HB, Derrington AM, Harris LR, Lennie P (1977) The effects of remote retinal stimulation on the responses of cat retinal ganglion cells. J Physiol (Lond) 269:177-194.

Benardete EA, Kaplan E, Knight BW (1992) Contrast gain control in the primate retina: $\mathrm{P}$ cells are not $\mathrm{X}$-like, some $\mathrm{M}$ cells are. Vis Neurosci 8:483-486.

Bloomfield SA (1996) Effect of spike blockade on the receptive-field size of amacrine and ganglion cells in the rabbit retina. J Neurophysiol 75:1878-1893.

Bolz J, Wässle H, Thier P (1984) Pharmacological modulation of ON and OFF ganglion cells in the cat retina. Neuroscience 12:875-885.

Brainard DH (1997) The psychophysics toolbox. Spat Vis 10:433-436.

Caldwell JH, Daw NW (1978) New properties of rabbit retinal ganglion cells. J Physiol (Lond) 276:257-276.

Cleland BG, Levick WR (1974) Brisk and sluggish concentrically organized ganglion cells in the cat's retina. J Physiol (Lond) 240:421-456.

Cohen E, Sterling P (1992) Parallel circuits from cones to the on-beta ganglion cell. Eur J Neurosci 4:506-520.

Cox JF, Rowe MH (1996) Linear and nonlinear contributions to step responses in cat retinal ganglion cells. Vision Res 36:2047-2060.

Dacey DM (1989) Axon-bearing amacrine cells of the Macaque monkey retina. J Comp Neurol 284:275-293.

Dacey DM, Lee BB (1994) The "blue-on" opponent pathway in primate retina originates form a distinct bistratified ganglion cell type. Nature 367:731-735.

Derrington AM (1984) Spatial frequency selectivity of remote pattern masking. Vision Res 24:1965-1968.

Derrington AM, Lennie P, Wright MJ (1979) The mechanism of peripherally evoked responses in retinal ganglion cells. J Physiol (Lond) 289:299-310.

Enroth-Cugell C, Jakiela HG (1980) Suppression of cat retinal ganglion cell responses by moving patterns. J Physiol (Lond) 302:49-72.

Enroth-Cugell C, Pinto LH (1970) Algebraic summation of centre and surround inputs to retinal ganglion cells of the cat. Nature 226:458-459.

Enroth-Cugell C, Robson JG (1966) The contrast sensitivity of retinal ganglion cells of the cat. J Physiol (Lond) 187:517-552.

Famiglietti EV (1992a) Polyaxonal amacrine cells of rabbit retina: morphology and stratification of PA1 cells. J Comp Neurol 316:391-405.

Famiglietti EV (1992b) Polyaxonal amacrine cells of rabbit retina: size and distribution of PA1 cells. J Comp Neurol 316:406-421.

Famiglietti EV (1992c) Polyaxonal amacrine cells of the rabbit retina: PA2, PA3, and PA4 cells. Light and electron microscopic studies with a functional interpretation. J Comp Neurol 316:442-446.

Fischer B, Kruger J, Droll W (1975) Quantitative aspects of the shifteffect in cat retinal ganglion cells. Brain Res 83:391-403.

Freed MA (1993) Noise analysis of ON-beta ganglion cell voltage responses. Invest Ophthalmol 34:1154.

Freed MA, Pflug R, Kolb H, Nelson R (1996) ON-OFF amacrine cells in the cat retina. J Comp Neurol 364:556-566.

Fuhr P, Kuyk T (1998) The contrast-response of the periphery effect. Vision Res 38:1983-1987.

Hamasaki DI, Maguire GW (1985) A neural pathway for the shift response in the cat. Brain Res 337:51-58.

Hartveit E, Brandstatter JH, Enz R, Wässle H (1995) Expression of the mRNA of seven metabotropic glutamate receptors (mGluR1 to 7) in the rat retina. An in situ hybridization study on tissue sections and isolated cells. Eur J Neurosci 7:1472-1483.

He ZJ, Loop MS (1990) Peripheral field stimulation affects foveal flicker, but not color, sensitivity. Vision Res 30:1107-1110.

Hochstein S, Shapley RM (1976) Linear and nonlinear spatial subunits in Y cat retinal ganglion cells. J Physiol (Lond) 262:265-284.

Jacobs GH, Deegan JFI (1994) Spectral sensitivity, photopigments, and color vision in the guinea pig (Cavia porcellus). Behav Neurosci 108:993-1004.

Jensen RJ (1991) Intracellular recording of light responses from visually identified ganglion cells in the rabbit retina. J Neurosci Methods 40:101-112.

Kao YH, Demb JB, Haarsma L, Johnson MA, Sterling P (1999) An axon-bearing amacrine cell tracer coupled to the OFF Y ganglion cell. Invest Ophthalmol 40:S813.

Kaplan E, Shapley RM (1982) X and Y cells in the lateral geniculate nucleus of Macaque monkeys. J Physiol (Lond) 330:125-143.

Knapp AG, Mistler LA (1983) Response properties of cells in rabbit's lateral geniculate nucleus during reversible blockade of retinal oncenter channel. J Neurophysiol 50:1236-1245.

Koulen P, Malitschek B, Kuhn R, Wässle H, Brandstatter JH (1996) Group II and group III metabotropic glutamate receptors in the rat retina: distributions and developmental expression patterns. Eur J Neurosci 8:2177-2187.

Kruger J (1977) The shift-effect in the lateral geniculate body of the rhesus monkey. Exp Brain Res 29:387-392.

Kruger J, Fischer B (1973) Strong periphery effect in cat retinal ganglion cells. Excitatory responses in ON- and OFF- center neurones to single grid displacements. Exp Brain Res 18:316-318.

Kruger J, Fischer B, Barth R (1975) The shift-effect in retinal ganglion cells of the rhesus monkey. Exp Brain Res 23:443-446.

Kuffler SW (1953) Discharge patterns and functional organization of mammalian retina. J Neurophysiol 16:37-68.

Mareschal I, Baker Jr CL (1998) A cortical locus for the processing of contrast-defined contours. Nat Neurosci 1:150-154.

Mareschal I, Baker Jr CL (1999) Cortical processing of second-order motion. Vis Neurosci 16:527-540.

McGraw PV, Levi DM, Whitaker D (1999) Spatial characteristics of the second-order visual pathway revealed by positional adaptation. Nat Neurosci 2:479-484.

McIlwain JT (1964) Receptive fields of optic tract axons and lateral geniculate cells: peripheral extent and barbiturate sensitivity. J Neurophysiol 27:1154-1173.

McIlwain JT (1966) Some evidence concerning the physiological basis of the periphery effect in the cat's brain. Exp Brain Res 1:265-271.

Nawy S, Jahr CE (1990) Suppression by glutamate of cGMP-activated conductance in retinal bipolar cells. Nature 346:269-271.

Nelson R, Kolb H (1983) Synaptic patterns and response properties of bipolar and ganglion cells in the cat retina. Vision Res 23:1183-1195.

Pelli DG (1997) The VideoToolbox software for visual psychophysics: transforming numbers into movies. Spat Vis 10:437-442.

Pu M, Berson D, Pan T (1994) Structure and function of retinal ganglion cells innervating the cat's geniculate wing: an in vitro study. J Neurosci 14:4338-4358.

Rodieck RW (1965) Quantitative analysis of cat retinal ganglion cell response to visual stimuli. Vision Res 5:583-601.

Rohlich P, van Veen T, Szel A (1994) Two different visual pigments in one retinal cone cell. Neuron 13:1159-1166.

Rowe MH, Cox JF (1993) Spatial receptive-field structure of cat retinal W cells. Vis Neurosci 10:765-769.

Schiller PH (1982) Central connections of the retinal ON and OFF pathways. Nature 297:580-583.

Shiells RA, Falk G, Naghshineh S (1981) Action of glutamate and aspartate analogues on rod horizontal and bipolar cells. Nature 294:592-594.

Slaughter MM, Miller RF (1981) 2-Amino-4-phosphonobutyric acid: a new pharmacological tool for retina research. Science 211:182-184.

So YT, Shapley R (1979) Spatial properties of X and Y cells in the lateral geniculate nucleus of the cat and conduction velocities of their inputs. Exp Brain Res 36:533-550.

Spitzer H, Hochstein S (1987) Visual receptive fields of cat cortical neurons lack the distinctive geniculate $\mathrm{Y}$ cell signature. Isr J Med Sci 23:69-74.

Stafford DK, Dacey D (1997) Physiology of the A1 amacrine: a spiking, 
axon-bearing interneuron of the macaque monkey retina. Vis Neurosci 14:507-522.

Sterling P (1998) Retina. In: The synaptic organization of the brain (Shepherd GM, ed), pp 205-253. New York: Oxford UP.

Sterling P, Johnson MA, Haarsma L, Kao YH, Demb JB (1999) Ganglion cell types of the guinea pig retina. Invest Ophthalmol 40:S814.

Stone C, Pinto LH (1993) Response properties of ganglion cells in the isolated mouse retina. Vis Neurosci 10:31-39.

Troy JB, Robson JG (1992) Steady discharges of X and Y retinal ganglion cells of cat under photopic illuminance. Vis Neurosci 9:535-553.

Troy JB, Einstein G, Schuurmans RP, Robson JG, Enroth-Cugell C (1989) Responses to sinusoidal gratings of two types of very nonlinear retinal ganglion cells of cat. Vis Neurosci 3:213-223.

Troy JB, Oh JK, Enroght-Cugell C (1993) Effect of ambient illumination on the spatial properties of the center and surround of Y-cell receptive fields. Vis Neurosci 10:753-764.

Troy JB, Schweitzer-Tong DE, Enroth-Cugell C (1995) Receptive-field properties of $\mathrm{Q}$ retinal ganglion cells of the cat. Vis Neurosci 12:285-300.
Vaney DI (1990) The mosaic of amacrine cells in the mammalian retina. In: Progress in retinal research, Vol 9 (Osborne NN, Chader G, eds), pp 49-100. Oxford: Pergamon.

Vaney DI, Peichl L, Boycott BB (1988) Neurofibrillar long-range amacrine cells in mammalian retinae. Proc $\mathrm{R}$ Soc Lond B Biol Sci 235:203-219.

Victor JD (1988) The dynamics of the cat retinal Y cell subunit. J Physiol (Lond) 405:289-320.

Victor JD, Shapley RM (1979a) Receptive field mechanisms of cat X and Y retinal ganglion cells. J Gen Physiol 74:275-298.

Victor JD, Shapley RM (1979b) The nonlinear pathway of Y ganglion cells in the cat retina. J Gen Physiol 74:671-689.

Wässle H, Boycott BB (1991) Functional architecture of the mammalian retina. Physiol Rev 71:447-480.

Watanabe J, Tasaki K (1980) Shift-effect in the rabbit retinal ganglion cells. Brain Res 181:198-201.

Werblin F (1972) Lateral interactions at inner plexiform layer of vertebrate retina: antagonistic responses to change. Science 175:1008-1010. 